\title{
Developmental disparities between stimulus-response and stimulus-stimulus conflicts processing during childhood, adolescence, and early adulthood
}

Di Fu' ${ }^{1,2,4 \#, ~ Y i ~ O u y a n g 1,2,3 \#, ~ G u o c h u n ~ Y a n g ~}{ }^{1,2}$, Guangteng Meng ${ }^{1,2}$, Stefan Wermter ${ }^{4}$, Yue

$$
\mathrm{Qi}^{* 1,2}, \text { Xun Liu }{ }^{1,2}
$$

1 CAS Key Laboratory of Behavioral Science, Institute of Psychology, Beijing, China.

2 Department of Psychology, University of Chinese Academy of Sciences, Beijing, China.

3 School of Education, Hunan University of Science and Technology, Hunan, China.

4 Department of Informatics, University of Hamburg, Germany

\#These authors contributed equally to this work.

*Correspondence:

Yue Qi, Institute of Psychology, Chinese Academy of Sciences, 16 Lincui Road, Chaoyang District.

Beijing, 100101, China. Email: qiy@psych.ac.cn

\section{Competing Interests:}

The authors declare no conflict of interest.

\section{Funding:}


The study design, analysis, and interpretation of data was supported by the National Natural Science Foundation of China (NSFC), and the German Research Foundation (DFG) under project Crossmodal Learning (NSFC 61621136008/DFG TRR 169) and CAS-DAAD joint fellowship. The data collection was funded by the Beijing Brain Initiative of Beijing Municipal Science and Technology Commission (Z181100001518003), Beijing Municipal Science and Technology Commission (Z161100002616023, Z171100000117012). Article writing and submission was funded by fund for building world-class universities (disciplines) of Renmin University of China. Project No. 2018, the Beijing Natural Science Foundation (5184035), and CAS Key Laboratory of Behavioral Science, Institute of Psychology.

\section{Data Availability Statement:}

Experimental program, original data, and statistical analyses results can be found on https://osf.io/n869w/.

Word count: 10,248, including the main text, figure captions, tables, references, and appendices 


\begin{abstract}
Conflict control is a critical capability for humans to detect and resolve conflicts. Unbalanced development of cognitive control may be associated with mental disorders and cause a heavy social burden. Despite the substantial amount of research on this topic, inconsistent conclusions were obtained from developmental trajectories of stimulus-response (S-R) conflict processing and stimulus-stimulus (S-S) conflict processing. This may be due to different tasks or relatively small population-based samples. Therefore, we designed a Simon-spatial-Stroop task and recruited 644 children, adolescents, and young adults from ages 7 to 23 to investigate consecutively developmental trajectories of different types of conflict processing. Our results demonstrated that all age groups showed robust stimulus-response compatibility (SRC) effects, and the task performance improved with faster response speed and enhanced accuracy with advancing age. It is noteworthy that the size of both S-R and S-S SRC effects declined from ages 7 to 15 , which suggested that the crucial developmental period is from early childhood to adolescence. Furthermore, both S-R and S-S conflicts processing followed a U-shaped function across ages and showed a distinct developmental pattern from age 7. The peak performance of S-S conflict processing (18.61 years) occurred earlier than S-R conflict processing (19.66 years), suggesting S-S conflict processing may mature earlier than S-R conflict processing. The current study provides a robust measurement of conflict control across a wide age range and advances our understanding of the developmental specificity of S-R and S-S conflict processing.
\end{abstract}

Keywords: stimulus-response compatibility, stimulus-stimulus compatibility, conflict processing, cognitive control, developmental trajectories, Simon-spatial-Stroop task 


\section{Introduction}

Cognitive control plays a crucial role in human's lifespan. Cognitive control enables human to adjust behavior flexibly and optimally according to the current goal in an uncertain environment (Egner, 2017; Fan, 2014). The dysfunction of the cognitive control system may result in many mental disorders, such as attention-deficit/hyperactivity disorder (ADHD), addiction, and misconduct behavior (Arias-Carrión \& Salama, 2012; Barkley, 1997; Gluckman, Hawes, \& Russell, 2016). Children's development of cognitive control is positively correlated with their conflict tasks performance, academic achievements, self-regulation, emotion regulation, and well-being (Posner \& Rothbart, 1998; Best, Miller, \& Naglieri, 2011; Bull \& Lee, 2014; Cragg \& Gilmore, 2014; Llewellyn, Lang, Langa, \& Huppert, 2008). Therefore, to study the development of cognitive control will contribute to an individual's mental health and achievement.

\subsection{SRC effects and S-R/S-S conflict processing}

The Stimulus-Response-Compatibility (SRC) tasks are used in laboratory research to measure the capacity of cognitive control. Based on the taxonomy frame of Domain Overlap (DO) theory (Kornblum, Hasbroucq, \& Osman, 1990), the SRC task could be classified by DO attributes as taskrelevant stimulus $(\mathrm{Sr})$, task-irrelevant stimulus $(\mathrm{Si})$ and response $(\mathrm{R})$. The Stroop task and the Flanker task belong to the Sr-Si (S-S) conflict task (Stroop, 1935), and the Simon task belongs to the Si-R (S-R) conflict task (Simon, 1969; Simon \& Rudell, 1967).

The SRC effect occurs when stimulus and response are incongruent, participants show inferior performance (i.e. worse accuracy and slower response) compared with congruent conditions (Wang, Li, Zheng, Wang, \& Liu, 2014). In the Stroop task, participants are asked to report the font color of the word ( $\mathrm{Sr}$ ) by ignoring the semantic meaning of the word ( $\mathrm{Si}$ ) (Sanders, Hortobágyi, Balasingham, 
Van Der Zee, \& Van Heuvelen, 2018). The SRC effect in the Stroop task is that, if the font color and semantic meaning of the word are incongruent (e.g., a "red" word written in the green color), participants show longer response time and worse accuracy than under the congruent condition (e.g., a "red" word written in the red color). Similarly, the SRC effect in the Simon task is that participants show longer reaction time and worse accuracy when locations of stimuli ( $\mathrm{Si}$ ) and response hand (R) are incongruent than congruent (Buetti \& Kerzel, 2009; Hommel, 2011; Richez, Olivier, \& Coello, 2016). The size of the SRC effect reflects the capacity of conflict processing. The larger SRC effect is accompanied by weaker top-down control, and dysfunction or immaturity of conflict control (Cohen, Dunbar, \& Mcclelland, 1990; Macleod, 1991; Mcneely, West, Christensen, \& Alain, 2003).

\subsection{Development of S-R conflict processing}

Previous conclusions about developmental differences of S-R conflict processing are not consistent. Studies using classical Simon tasks observed significant SRC effects from early childhood (Davidson, Amso, Anderson, \& Diamond, 2006; Erb \& Marcovitch, 2018b; Smulders, Soetens, \& Van Der Molen, 2018). For instance, Davidson et al. (2006) found a significant S-R SRC effect during the Simon task from age 4, and the size of the SRC effect decreased with advancing age until age 13 . These results suggest that the S-R conflict processing capacity developed until middle childhood and early adolescence. However, Richez et al. (2016) used a modified Simon task to test 8- to 12-year-old participants. Different from the classic Simon task, locations of stimulus and response keys were presented either on the proximal or the distal side of participants. Their results showed that the SRC effect was only observed older than 10 years but not children from 8 to 10 years.

\subsection{Development of S-S conflict processing}


For the development of S-S conflict processing, previous conclusions are not consistent either. For instance, one study using a modified robots Flanker task tested 4-6, 7-9, and 10-13 age groups and compared their behavioral and event-related potential (ERP) results with adults (Checa, Castellanos, Abundis-Gutiérrez, \& Rosario Rueda, 2014). During the task, participants were asked only to indicate whether the robot in the middle was round or square. Their behavioral and neural results both proved the growing conflict control capacity with advanced age with decreasing SRC effect, shorter reaction time, lower N450 amplitude, and larger error-related negativity (ERN). The 4-6 age group showed a significantly larger SRC effect than adults and marginally larger than the 10-13 age group, but no significant difference between the 10-13 age group and adults was observed. Their results implied that S-S conflict processing capacity kept improving until middle childhood and early adolescence (10-13 age group). However, some research found protracted maturity of SS conflict processing in adolescence or adulthood (Hämmerer, Müller, \& Li, 2014; Li, Hämmerer, Müller, Hommel, \& Lindenberger, 2009; Reuter et al., 2019). For instance, an ERP study tested youth (ages 8-18), younger adults (ages 20-28), and older adults (ages 56-91) by the Flanker task. They found that the peak cognitive performance (shortest reaction time and best accuracy) and processing efficiency (reduced correct-response negativity, reduced N2 amplitude, and increased error-positivity amplitude) appeared in younger adulthood rather than youth and older adults (Clawson, Clayson, Keith, Catron, \& Larson, 2017).

\subsection{Developmental differences between $S-R$ and $S-S$ conflict processing}

Several studies directly compare developmental differences of S-R and S-S conflicts processing by using one single task. However, no consensus has been reached on the developmental disparity between S-R and S-S conflicts processing. Some studies demonstrated that S-S conflict control 
matured earlier than S-R conflict control (Davies, Segalowitz, \& Gavin, 2004; Ridderinkhof \& Van Der Molen, 1995; Liu et al., 2018). For example, one ERP study used a Color-Object-Stroop task and reported that S-S conflict control reached maturity in early childhood (ages 6-7) and S-R conflict control continued developing into adolescence (Jongen \& Jonkman, 2008). Similarly, one study (Bryce, Szucs, Soltesz, \& Whitebread, 2011) used an animal Stroop task and found that S-S conflict control matured by age 5 and S-R conflict processing matured after age 8. On the contrary, Cragg (2016) used a modified color Flanker task (Verbruggen, Notebaert, Liefooghe, \& Vandierendonck, 2006) found that S-R conflict control matured earlier than S-S conflict control by testing 7-, 10-, and 20-year-olds. The results showed no developmental changes of S-R conflict processing, but SS conflict processing reached the adult level by age 10. In sum, although more research findings support that S-S conflict control may develop and reach maturity earlier than S-R conflict control, further empirical evidence is needed.

\subsection{Summaries of previous research and the current study}

Several limits exist in previous research. Firstly, considering the inhomogeneity of cognitive representations within Stroop-like, Flanker-like, and Simon-like tasks (Derrfuss, Brass, Neumann, \& Von Cramon, 2005), it is not rigorous to compare S-R and S-S tasks performance by different tasks with inconsistent stimuli. Designing paradigms with consistent stimuli, difficulties, and normalizing the performance is essential. Secondly, inconsistent conclusions of maturity of S-R and S-S conflict processing could be accounted by the limited stimulus set size and smaller difficulty of the task, which leads to a developmental ceiling on the performance (Gerstadt, Hong, \& Diamond, 1994; Macleod, 1991; Wright, Waterman, Prescott, \& Murdoch-Eaton, 2003). Thirdly, the lack of consecutive age measurement could also result in inconsistent conclusions. Comparing performance 
between two or three age groups from young children and adults may miss the crucial developmental period, such as adolescence (Berenbaum, Beltz, \& Corley, 2015; Vijayakumar, Op De Macks, Shirtcliff, \& Pfeifer, 2018).

To improve the above limitations, the gist of our research is to draw the developmental trajectories of conflict processing during childhood, adolescence, and early adulthood and compare the developmental difference between S-R and S-S conflict processing. In the current study, we collected a large sample size of 644 participants across diverse age spans from 7 to 23 years with their performance on the Simon-spatial-Stroop task.

We hypothesize that compared with adolescents and young adults, children would show larger magnitude of SRC effects in both S-R and S-S conflicts processing depending on their immature cognitive control function. In addition, considering that adolescence is a crucial period with rapid physical and psychological development (Huizinga, Dolan, \& van der Molen, 2006; Aite et al., 2018; Erb \& Marcovitch, 2018a), conflict processing may be fully developed into adolescence or early adulthood. Furthermore, based on the theoretical assumption and empirical findings, we expect that S-S conflict processing matures earlier than S-R conflict processing.

\section{Method}

\subsection{Participants}

Data of 644 participants entered final statistical analyses in the current study. Another 57 participants were excluded from the final analysis $(8.9 \%)$ because of the lack of concentration (task accuracy reached $80 \%$ during the practice but under $50 \%$ in the formal test). Participants were divided into 5 age groups, which conformed to the age classification from the World Health Organization (Ahmad et al., 2001). Specifically, they were: 7-9 years group $(\mathrm{M} \pm \mathrm{SD}=7.97 \pm .83)$, 
10-12 years group $(\mathrm{M} \pm \mathrm{SD}=10.99 \pm .83), 13-15$ years group $(\mathrm{M} \pm \mathrm{SD}=13.99 \pm .84), 16-18$ years group $(\mathrm{M} \pm \mathrm{SD}=16.89 \pm .80)$, and 19-23 years group $(\mathrm{M} \pm \mathrm{SD}=20.35 \pm 1.23)$ (details see table 1). All the participants were recruited in local schools and colleges in Hunan province, China. Parents were asked to sign the informed consents for their children, and adults were asked to sign the consents by themselves. All participants had a normal or corrected-to-normal vision and reported no history of neurological diseases or any cognitive disorders. The study was approved by the Institutional Review Board of the Institute of Psychology, [blinded], and followed the Declaration of Helsinki (granting body: [blinded] Municiple Science and Tech Commission; protocol number: Z161100002616023, Z171100000117012; title of study: [blinded] Project - Grow Up in [blinded]). Table 1 Participants' information

\begin{tabular}{cccc}
\hline $\begin{array}{c}\text { Age groups } \\
\text { (years) }\end{array}$ & $\begin{array}{c}\text { Total } \\
\text { (proportion of the } \\
\text { total number) }\end{array}$ & Male & $\begin{array}{c}\text { Female } \\
\text { (proportion of the } \\
\text { age group) }\end{array}$ \\
\hline $7-9$ & $110(17.1 \%)$ & 52 & $58(52.7 \%)$ \\
$10-12$ & $145(22.5 \%)$ & 74 & $71(49.0 \%)$ \\
$13-15$ & $160(24.8 \%)$ & 86 & $74(46.3 \%)$ \\
$16-18$ & $114(17.7 \%)$ & 53 & $61(53.5 \%)$ \\
$19-23$ & $115(17.9 \%)$ & 45 & $70(60.9 \%)$ \\
Total & 644 & 311 & $334(51.9 \%)$ \\
\hline
\end{tabular}

\subsection{Task and Procedure}

Simon-spatial-Stroop task. Stimulus display and the response recording were both under the control of E-prime 2.0. Corresponding to the previous study (Wang et al., 2014), stimuli colored in white appeared with a gray background (visual angle, $4.9^{\circ} \times 4.9^{\circ}$ ). In each trial, a fixation cross firstly came out in the middle of the screen for 100-300ms randomly, followed by an arrow presented at one of the four possible locations: left, right, top, and bottom for $800 \mathrm{~ms}$ (see Fig. 1, left). Considering children respond slowly because of their developing cognitive function, the current 
target display time was set longer than the previous adult Simon-spatial-Stroop task (Liu, Banich, Jacobson, \& Tanabe, 2004; Wang et al., 2014). Participants were instructed to respond to the orientation of the arrow by pressing one of two response keys on the computer keyboard with their left or right index finger, respectively. For half of the participants in each age group, they were instructed as "Z" for upward arrow and "/" for downward arrow, while the other half were instructed oppositely. At last, another fixation ending displayed for $700-900 \mathrm{~ms}$ as the remainder of the end of the trial. The time duration for each trial was $1600-2000 \mathrm{~ms}$, and the formal test lasted for 15 mins.

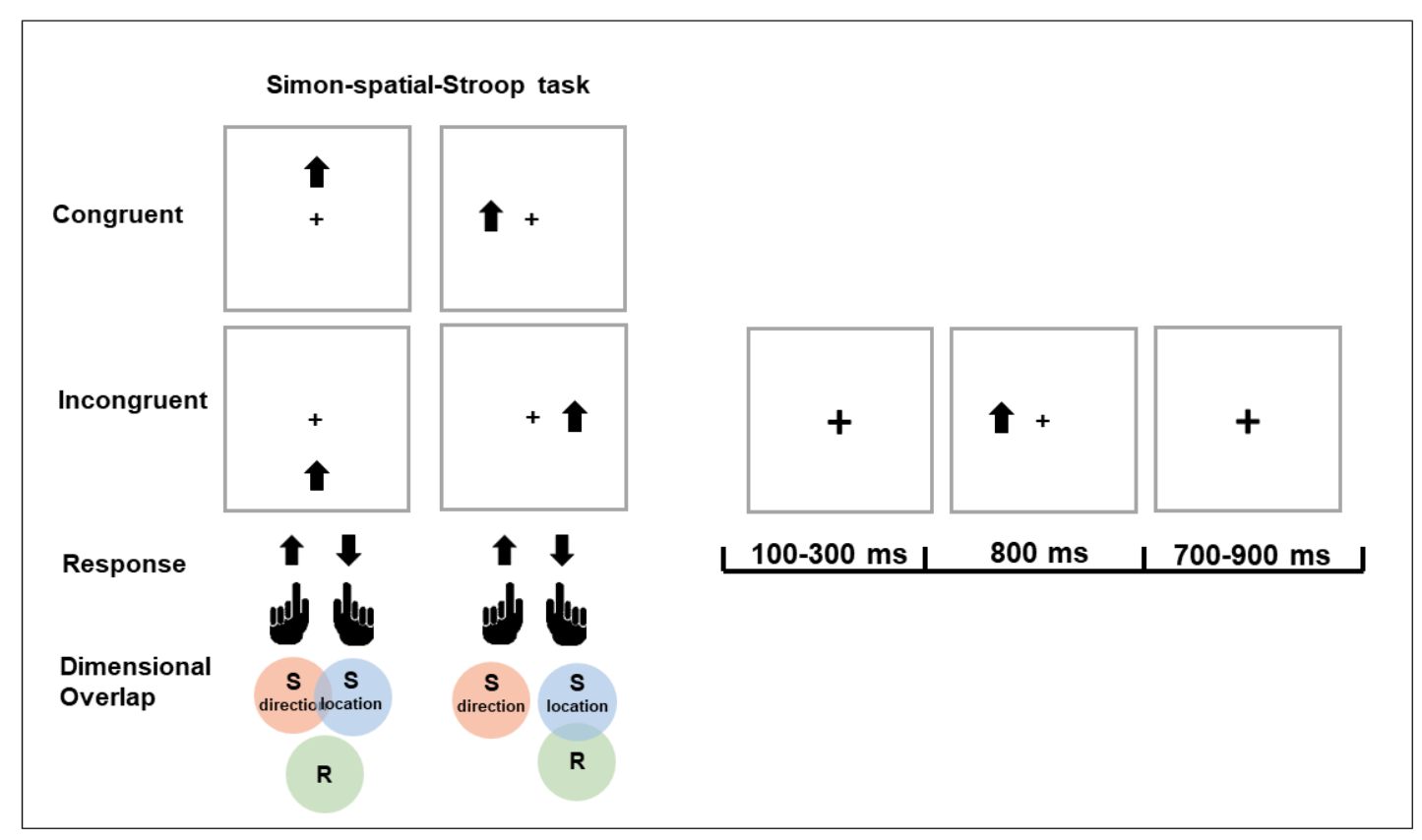

Figure 1. Experimental design. Experimental stimuli and congruent or incongruent S-S/S-R conditions (left). The schematic diagram of one trial in the Simon-spatial-Stroop task (right).

The arrow orientation-location arrangements in the experimental design could be categorized into four conditions. (1) Stimulus-Stimulus Congruent (SSC): the two stimulus dimensions (StimulusStimulus) overlapped as congruent (e.g., an upward arrow showed above the fixation). (2) StimulusStimulus Incongruent (SSI): the two stimulus dimensions overlapped as incongruent (e.g., an 
upward arrow showed below the fixation). (3) Stimulus-Response Congruent (SRC): the stimulus location overlapped with the response (Stimulus-Response) as congruent (e.g., an upward arrow responded by the left index finger shown on the left side of the screen). (4) Stimulus-Response Incongruent (SRI): the stimulus location overlapped with the response as incongruent (e.g., an upward arrow responded by the left index finger shown on the right side of the screen). Each condition was repeated 80 times, with a total of 320 trials separated into 4 blocks. Several studies used the pseudorandomized experimental design to prevent the feature integration confounder over repeated trials (Liu et al., 2018; Yang et al. 2017). However, in the current study, we are only concerned about the SRC effect but not with the sequential effect in conflict processing, so no feature integration effect is involved. Thus, the random experimental design was used to display stimuli as previous research (Wang et al., 2014; Liu, Park, Gu, \& Fan, 2010). Participants began the experiment with 20 practice trials and ended into the formal test until their accuracy of practice trials reached $80 \%$. Reaction time (RT) and error rate (ER) were recorded as measurements.

\subsection{Data analysis}

Reaction Time (RT), error rates (ER), and IES (inverse efficiency score) were analyzed as response indexes. For the RT analysis, we followed the methods from previous studies (Funes, Lupianez, \& Humphreys, 2010; Hazeltine, Lightman, Schwarb, \& Schumacher, 2011; Wang et al., 2014; Yang et al., 2017), error trials and trials with RTs shorter than $200 \mathrm{~ms}$ and beyond 3 SDs were not included (2.3\%). The calculation of the IES is dividing the mean RT by Accuracy (1-ER), which is considered an efficient approach to combine the RT and the ER results (Townsend \& Ashby, 1978, 1983). IES takes effect when the number of errors is small and when the trends of RT and ER point in the same direction (Bruyer \& Brysbaert, 2011). Considering the current results conform to the 
analysis requirements, we calculated the IES results to provide a more straightforward interpretation of our research findings. RT and ER results can be found in appendices. All post hoc tests in the current study used the Bonferroni correction.

To examine whether the SRC effect existed across the age span, 5 (age groups: 7-9/10-12/1315/16-18/19-23 years) $\times 2($ conflict types: S-R/S-S $) \times 2$ (congruency: congruent/incongruent) mixed design ANOVAs were performed on RT, ER, and IES. All the age groups showed significant SRC effects in both S-R and S-S conflict conditions, all $p s<.001$. Because we are concerned more about the developmental differences between S-R and S-S conflicts processing, results of this part are reported in Appendix A.

Comparison between S-R and S-S SRC effect across the age span. 5 (age groups: 7-9/1012/13-15/16-18/19-23 years $) \times 2($ conflict types: S-R/S-S $) \times 2$ (gender: male/female) mixed design ANOVA was performed on normalized SRC effects. The normalized SRC effect of each participant was obtained by dividing the SRC effect by his/her mean response of each trial as: (incongruent congruent)/ mean (Bryce et al., 2011). In doing so, individual performance under different types of conflicts can be compared directly.

Respective developmental changes of S-R and S-S SRC effect. One-way ANOVAs of the age group were performed on mean response, and SRC effects of IES for S-R conflict and S-S conflict, respectively. Mean response was measured by averaging response of both congruent and incongruent conditions within S-R/S-S conflict. SRC effects were measured by subtracting congruent from incongruent data ("I - C" is short for "incongruent minus congruent data").

Developmental disparities between S-R and S-S conflict processing. Firstly, to examine the 
individual differences between the two types of conflict processing, Pearson correlation analyses were performed on mean response and SRC effects between S-R and S-S conflicts across the age span. Additionally, general linear regression model analyses were conducted to examine linear, quadratic, and cubic changes in SRC effects predicted by age. The linear regressions modeled the S-R and the S-S normalized SRC effect values respectively with (1) age, (2) age ${ }^{2}$, and (3) age as predictors to explore the best-fitting model and predict the exact maturity ages of S-R and S-S conflict processing (Davies et al., 2004; Zuo et al., 2010).

\section{Results}

\subsection{Comparison between S-R and S-S SRC effect across the age span}

The main effect of the age group was significant $\left(F(4,639)=52.25, p<.001, \eta_{\mathrm{p}}{ }^{2}=.26\right)$. Post hoc tests indicated that 7-9 years $(\mathrm{M} \pm \mathrm{SE}=1.48 \pm .06 \mathrm{~ms})$ showed significant larger SRC effects than $13-15(\mathrm{M} \pm \mathrm{SE}=.84 \pm .04 \mathrm{~ms}), 16-18(\mathrm{M} \pm \mathrm{SE}=.69 \pm .05 \mathrm{~ms})$, and $19-23$ years $(\mathrm{M} \pm \mathrm{SE}=.70$ $\pm .05 \mathrm{~ms}), p s<.001$, but not $10-12$ years $(\mathrm{M} \pm \mathrm{SE}=1.35 \pm .05 \mathrm{~ms}, p=.84) .10-12$ years showed significantly larger SRC effects than 13-15 years, 16-18, and 19-23 years, $p s<.001$. But the differences between 13-15, 16-18 and 19-23 years were all not significant, $p s>.05$. The main effect of the conflict type was not significant $\left(F(1,642)=.11, p=.74, \eta_{\mathrm{p}}{ }^{2}=.00\right)$, indicating participants showed similar $\mathrm{SRC}$ effects between $\mathrm{S}-\mathrm{R}$ conflict $(\mathrm{M} \pm \mathrm{SE}=1.02 \pm .03 \mathrm{~ms})$ and $\mathrm{S}-\mathrm{S}$ conflict $(\mathrm{M} \pm$ $\mathrm{SE}=1.00 \pm .04 \mathrm{~ms})$. The main effect of gender was not significant $\left(F(1,642)=.02, p=.90, \eta_{\mathrm{p}}{ }^{2}\right.$ $=.00)$, indicating no significant performance difference was observed between female $(\mathrm{M} \pm \mathrm{SE}=$ $1.02 \pm .03 \mathrm{~ms})$ and male participants $(\mathrm{M} \pm \mathrm{SE}=1.01 \pm .03 \mathrm{~ms})$. The interaction effect between age group and conflict type was significant, $F(4,639)=2.51, p<.05, \eta_{\mathrm{p}}^{2}=.02$. The simple effect 
analysis showed that only for 7-9 years, participants had higher SRC effects with S-R conflict (M \pm $\mathrm{SE}=1.62 \pm .07 \mathrm{~ms})$ than $\mathrm{S}-\mathrm{S}$ conflict $(\mathrm{M} \pm \mathrm{SE}=1.34 \pm .09 \mathrm{~ms}), p<.01$. After age 9, there was no difference between S-R and S-S conflict processing, $p s>.05$. No significant interaction effect was observed between gender and age group $\left(F(4,642)=1.62, p=.90, \eta_{\mathrm{p}}{ }^{2}=.00\right)$ nor between gender and conflict type $\left(F(1,642)=.32, p=.57, \eta_{\mathrm{p}}{ }^{2}=.001\right)$. Thus, to simplify and clarify the visualization of results, Fig. 2 only showed differences of SRC effects between age groups and conflict types. Results of RT and ER are reported in Appendix B.

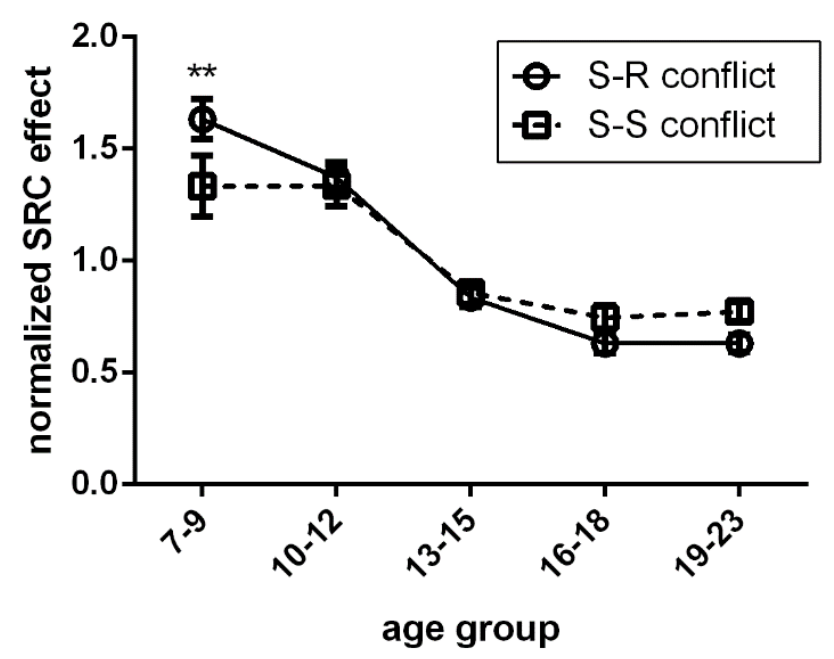

Figure 2. Comparison between S-R and S-S SRC effect across the age span. Only 7-9 years showed significantly higher SRC effects in S-R conflict processing than S-S conflict processing ( $p$ $<.01)$. Labels and legends are the same as in Table $2 .{ }^{*}$ denotes $.01<p<.05,{ }^{* *} .001<p<.01,{ }^{* * *}$ $p<.001$. 


\subsection{Respective developmental changes of S-R and S-S SRC effects}

Table 2 showed the means, standard deviations, and SR/SS SRC effects of IES under different conflict conditions in each age group.

Table 2 Means, Standard Deviations, and SR/SS SRC effects of IES for each age group

Notes. $\mathrm{SRC}=$ Stimulus-Response Congruent, $\mathrm{SRI}=$ Stimulus-Response Incongruent, $\mathrm{SR}(\mathrm{I}-\mathrm{C})=$ $\mathrm{SRI}$ - SRC, mean $\mathrm{SR}=$ mean response of SR conditions, $\mathrm{n} . \mathrm{SR}(\mathrm{I}-\mathrm{C})=$ normalized (SRI - SRC); $\mathrm{SSC}=$ Stimulus-Stimulus Congruent, $\mathrm{SSI}=$ Stimulus-Stimulus Incongruent, SS(I - C) = SSI - SSC; mean SS = mean response of SS conditions, $\mathrm{n} . \mathrm{SS}(\mathrm{I}-\mathrm{C})=$ normalized $(\mathrm{SSI}-\mathrm{SSC})$

\begin{tabular}{cccccc}
\hline Measure & $7-9$ year-old & $10-12$ year-old & $13-15$ year-old & 16-18 year-old & 19-23 year-old \\
\hline SRC & $892(149)$ & $729(115)$ & $515(52)$ & $519(64)$ & $516(55)$ \\
SRI & $1148(241)$ & $918(182)$ & $624(85)$ & $601(73)$ & $598(73)$ \\
SR(I - C) & $257(188)$ & $189(138)$ & $109(70)$ & $82(62)$ & $82(53)$ \\
mean SR & $1020(177)$ & $823(136)$ & $569(61)$ & $560(61)$ & $557(59)$ \\
n. SR(I - C) & $1.63(.87)$ & $1.37(.81)$ & $.84(.54)$ & $.63(.47)$ & $.63(.41)$ \\
SSC & $961(197)$ & $763(121)$ & $531(60)$ & $524(60)$ & $522(57)$ \\
SSI & $1078(218)$ & $862(149)$ & $593(59)$ & $579(61)$ & $578(59)$ \\
SS(I - C) & $117(135)$ & $99(85)$ & $62(46)$ & $54(42)$ & $56(34)$ \\
mean SS & $1020(196)$ & $812(129)$ & $562(55)$ & $552(57)$ & $550(55)$ \\
n. SS(I - C) & $1.33(1.32)$ & $1.34(1.10)$ & $.86(.64)$ & $.75(.58)$ & $.77(.47)$ \\
\hline
\end{tabular}

S-R conflict (see Table 2). The main effect of age on mean response was significant, $F(4,639)$ $=444.47, p<.001$. Post hoc tests indicated that 7-9 years had significantly longer mean response than $10-12,13-15,16-18$, and 19-23 years, $p s<.001 .10-12$ years had significantly longer mean response than $13-15,16-18,19-23$ years, $p s<.001$. There were no significant differences between every two groups among 13-15, 16-18 and 19-23 years, $p s>.05$. The main effect of age on SRC effects was significant, $F(4,639)=54.06, p<.001 .7-9$ years had significantly larger SRC effects than $10-12,13-15,16-18$, and 19-23 years, $p s<.001 .10-12$ years had significantly larger SRC effects than 13-15, 16-18, and 19-23 years ( $p s<.001$ ). Differences between 13-15, 16-18 and 19- 
23 years were not significant, $p s>.05$ (see Fig. 3).

S-S conflict (see Table 2). The main effect of age on mean response was significant, $F(4,639)$ $=435.33, p<.001$. Post hoc tests indicated that 7-9 years had significantly longer mean response than $10-12,13-15,16-18$, and 19-23 years, $p s<.001 .10-12$ years had significantly longer mean IES than 13-15, 16-18, and 19-23 years, $p s<.001$. Differences between 13-15, 16-18 and 19-23 years were not significant, $p s>.05$. The main effect of age on SRC effects was significant, $F(4,639)$ $=17.12, p<.001 .7-9$ years had significantly larger SRC effects than 13-15, 16-18, and 19-23 years, $p s<.001$, but not 10-12 years, $p=.57 .10-12$ years had significantly larger SRC effects than 13-15, 16-18, and 19-23 years, $p s<.001$. Differences between 13-15, 16-18 and 19-23 years were not significant, $p s>.05$ (see Fig. 3). Results of RT and ER are reported in Appendix C.
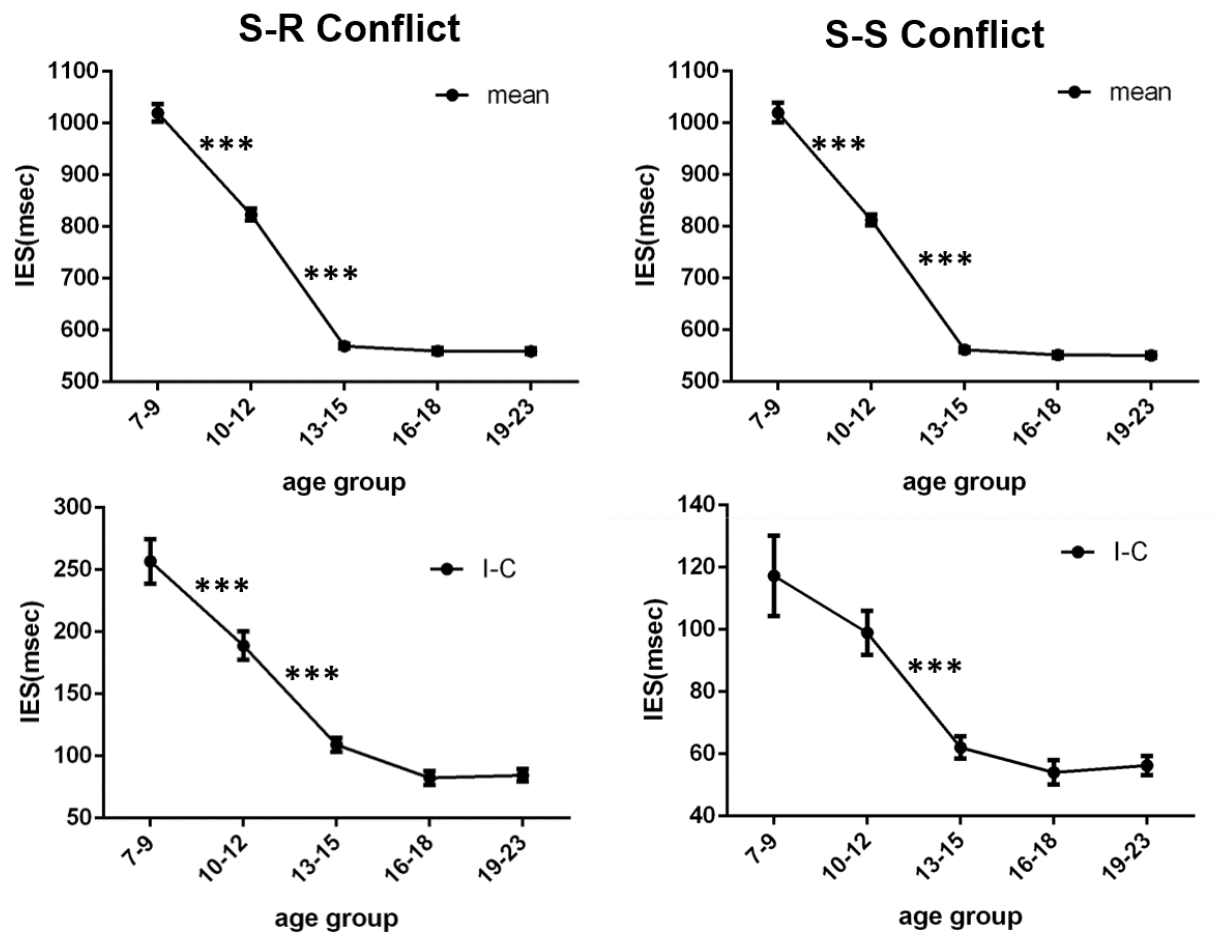

Figure 3. Respective developmental changes of S-R (left) and S-S (right) conflicts processing.

Mean response (up) and SRC effects (down) across different age groups are displayed. "I - C" is 
short for "incongruent minus congruent". Labels and legends are the same as in Table 2. * denotes $.01<p<.05,{ }^{* *} .001<p<.01,{ }^{* * *} p<.001$. Significance was only labeled between adjacent age groups.

\subsection{Disparities of development between S-R and S-S conflict processing}

Table 3 summarizes Pearson correlation coefficients and significance between S-R and S-S mean response and SRC effects of IES. For mean response, correlation coefficients were significant for each age group (all $p s<.001$ ). However, correlation coefficients of SRC effects were not significant across all age groups (all ps $>.05$ ). Results of RT and ER are reported in Appendix D.

Table 3 Pearson correlation coefficients between $S-R$ and $S-S$ mean response and $S R C$ effects

\begin{tabular}{cccccc}
\hline$r$-Correlation & $7-9$ year-old & $10-12$ year-old & $13-15$ year-old & $16-18$ year-old & $19-23$ year-old \\
\hline mean response & $.92^{* * *}$ & $.92^{* * *}$ & $.90^{* * *}$ & $.92^{* * *}$ & $.94^{* * *}$ \\
SRC & .04 & .14 & -.01 & .17 & .04 \\
\hline
\end{tabular}

Notes. ${ }^{*}$ denotes $.01<p<.05,{ }^{* *} .001<p<.01,{ }^{* * *} p<.001$

Table 4 summarized results of General Linear Model analyses (multivariate regression analysis). The regression analyses showed that the quadratic fitting was the best-fitting model to predict normalized SRC effects based on age (7-23 years rather than age groups). For S-R conflict, $R^{2}=.28, F(4,639)=120.82, p<.001$; for S-S conflict, $R^{2}=.13, F(4,639)=36.82, p<.001 . R^{2}$ of the linear model was smaller than the quadratic model (for S-R conflict, $R^{2}=.24, F(4,639)=199.48$, $p<.001$; for S-S conflict, $\left.R^{2}=.10, F(4,639)=69.80, p<.001\right) . R^{2}$ of the cubic model is same with the quadratic model (for S-R conflict, $R^{2}=.28, F(4,639)=80.79, p<.001$; for S-S conflict, $R^{2}=.13$, $F(4,639)=31.19, p<.001)$, however, all coefficients of independent variables in the cubic model were not significant. Thus, the quadratic model was adopted. According to previous developmental research, peak values of the u-shape curves were computed to represent the maturity age for the 
cognitive function (Waszak, Li, \& Hommel, 2010; Zuo et al., 2010). Thus, the maturity ages for SR and S-S conflict processing were 19.66 years and 18.61 years, respectively (see Fig. 4).

Table 4 Results of General Linear Model analyses of S-R and S-S SRC effects predicted by age

\begin{tabular}{|c|c|c|c|c|c|c|c|c|}
\hline \multirow[b]{2}{*}{ Variables } & \multicolumn{2}{|c|}{$\begin{array}{c}\text { Unstandardized } \\
\text { coefficients }\end{array}$} & \multicolumn{2}{|c|}{$\begin{array}{l}\text { Standardized } \\
\text { coefficients }\end{array}$} & \multirow[b]{2}{*}{$R^{2}$} & \multirow[b]{2}{*}{$\begin{array}{c}R^{2} \\
\text { change }\end{array}$} & \multirow[b]{2}{*}{$F$} & \multirow[b]{2}{*}{$p$} \\
\hline & $B$ & $S E$ & $\beta$ & $p$ & & & & \\
\hline n. SR(I - C) & & & & & .28 & .27 & 121.11 & $.00^{* * *}$ \\
\hline Constant & 4.05 & .31 & & $.00^{* * *}$ & & & & \\
\hline Age & -.35 & .05 & -1.76 & $.00^{* * *}$ & & & & \\
\hline $\mathrm{Age}^{2}$ & .01 & .002 & 1.29 & $.00^{* * * *}$ & & & & \\
\hline n. SS(I - C) & & & & & .13 & .13 & 46.86 & $.00^{* * *}$ \\
\hline Constant & 3.73 & .39 & & $.00^{* * * *}$ & & & & \\
\hline Age & -.34 & .06 & -1.45 & $.00^{* * * *}$ & & & & \\
\hline $\mathrm{Age}^{2}$ & .01 & .002 & 1.15 & $.00^{* * * *}$ & & & & \\
\hline
\end{tabular}

Notes. n. SR(I - C) = normalized (SRI - SRC); n. SS(I - C) $=$ normalized (SSI - SSC); ${ }^{*}$ denotes .01

$<p<.05,{ }^{* *} .001<p<.01,{ }^{* * *} p<.001$

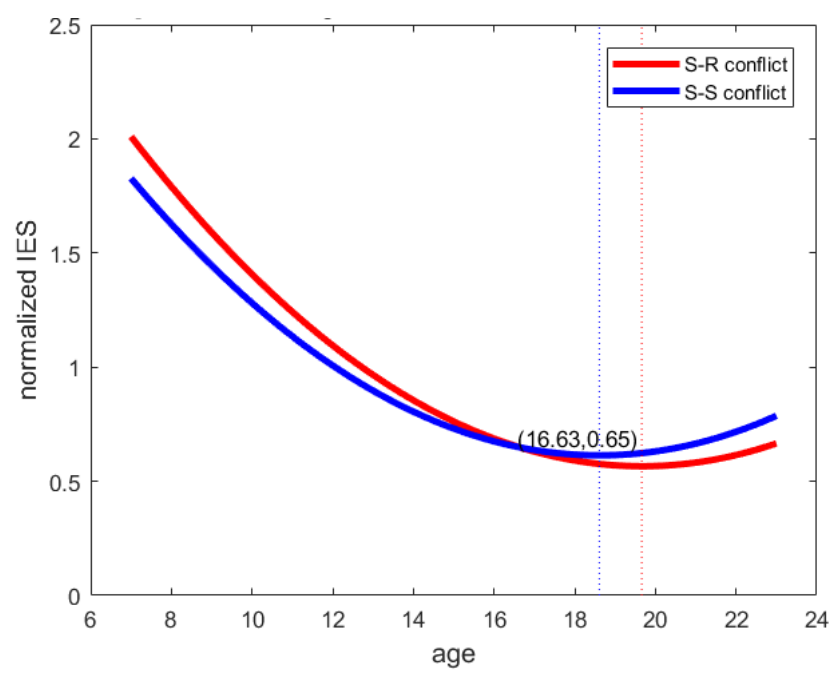

Figure 4. Developmental trajectories of S-R and S-S conflicts processing. Quadratic fittings were applied to the regression models of S-R and S-S conflicts changing by ages. The blue and red dashed lines denote the critical age for the S-S (18.61 years) and S-R (19.66 years) conflicts processing development, respectively. S-R conflict effect predicted by age: $y=0.009 x^{2}-0.354 x+$ 
4.407, $R^{2}=.28$; S-S conflict effect predicted by age: $y=0.009 x^{2}-0.335 x+3.731, R^{2}=.13$. The intersection point between these two developmental trajectories is 16.63 years. Compared with the S-R conflict trajectory, the S-S conflict trajectory changes more gradually and reaches to the vertex earlier.

\section{Discussion}

The current study displayed and compared the developmental trajectories of S-R and S-S conflicts processing by using the Simon-spatial-Stroop task on 7- to 23-year-olds. Firstly, our results showed that S-R and S-S SRC effects existed in all age groups robustly and decreased with increasing ages. Secondly, adolescence from 13- to 15-year-olds showed adult-like performance on both S-R and S-S conflict processing, suggesting that the critical developmental period for conflict processing was from middle childhood to young adolescence. The capacity reached full maturity until young adulthood. Lastly, developmental disparities of S-R and S-S conflicts processing implied a domain-specific pattern from an early age. The full maturity of S-S conflict processing might be earlier than S-R conflict processing.

Corresponding to previous findings (Davies et al., 2004; Rueda, Posner, Rothbart, \& DavisStober, 2004; Wright, 2017; Wright et al, 2003), our study observed the decreasing SRC effects of S-R and S-S conflict processing from children to adolescents and adults, suggesting that the Simonspatial-Stroop task provided a robust measurement of the SRC effect. The poorer performance of young participants due to the delayed maturation of anterior cingulate cortex (ACC) and dorsal lateral prefrontal cortex (dlPFC), which are involved in conflict monitoring and conflict resolution, respectively (Botvinick, Braver, Barch, Carter, \& Cohen, 2001; Davies et al., 2004; Hämmerer et 
al , 2014; Rueda et al., 2004).

For S-R conflict processing, our study found that adolescence (13-15 years) showed adult-like performance, and young adulthood (19.66 years) reached peak performance. This is consistent with the study of Davidson et al. (2006). In their study, they tested the response inhibition development of young participants from ages 4 to 13 and adult by the Simon task. They found that the SRC effect was still significantly larger for 13 -year-olds than adults. This might be interpreted as younger participants had poorer inhibition control and may use verbal mediation as a strategy to help them match the stimulus to response. Moreover, another research conducted an antisaccade task to exclude any semantic confounding, also found adult-level mature performance at around 14 years (Luna, Garver, Urban, Lazar, \& Sweeney, 2004). The developmental difference ascribed to the increasing integration of distributed cognitive processing associated brain regions during adolescence and adulthood (Luna et al., 2001). However, one study (Bossert, Kaurin, Preckel, \& Frings, 2014) used a more difficult task and found no significant S-R SRC development across ages 7-8, 9-10, and 11-12. Children had to memorize four stimulus-response mappings in their study, which is difficult than our study. The increased difficulty may decrease the SRC effect by lowering both compatible and incompatible responses (Davidson et al., 2006). Besides, there was no adults group to be compared performance with in Bossert et al. (2014).

Similarly, for S-S conflict processing, we found that adolescence (13-15 years) showed adultlike performance, and the peak performance occurred in young adulthood (18.61 years). It is consistent with one study tested 7-, 11-, 15-, and 21-year-olds by Flanker task, which found that 15year-olds showed no performance difference compared to adult (Huizinga et al., 2006). These can be interpreted as S-S conflict processing relies on the maturation of top-down inhibition control, 
which is still immature in adolescence (Velanova, Wheeler, \& Luna, 2009). Furthermore, the peak performance we found in young adulthood is also consistent with previous research with life span samples. Most of them found the U-shape distribution for conflict processing capacity ( $\mathrm{Li}$ et al., 2009; Reuter et al., 2019; Waszak et al., 2010). Compared with both ends, young adulthood shows the best conflict performance and lowest conflict cost. For instance, Reuter et al. (2019) collected behavioral and EEG data of 211 participants from 8 to 83 years by the colored Flanker task and found that young adults (20-29 years) had the highest speed and accuracy. Their further regression analyses showed that the peak performance of young adults can attribute to a higher cognitive processing speed than children, and more cognitive resources to update and evaluate the stimulus category than older adults. However, some research found earlier maturity in middle childhood or early childhood (Jogen \& Jonkman, 2008; Liu et al., 2018). These may be due to their task difficulty, which was too easy for young children. For instance, Liu et al. (2018) found no performance difference between adults and age 10 on a child-friendly fish flanker task. The arrow stimuli in our task are relatively more abstract and more difficult for young children to process, thus the adult-like performance appeared until adolescence.

Conflict processing showed domain-specific processing patterns from an early age. From our correlation analysis, S-R and S-S congruency effects were not developmentally correlated across all age spans, which implied a domain-specific pattern since age 7 . Some studies pointed out that children's executive function and cognitive processing become more refined and domain-specific as growing (Aite et al., 2018; Jongen \& Jonkman, 2008; Larson, Clawson, Clayson, \& South, 2012). For instance, Akshoomoff et al. (2018) examined cognitive flexibility and conflict control of 3-6, 79, 10-13, 14-17 and 18-21 age groups by using the NIH Toolbox Cognition Battery (NTCB) 
measures. They found that the performance of the 3-6 age group on multiple cognitive tasks was less differentiated than other older groups, which demonstrated that the functional specialization advanced as developing. Even though our current study did not test children younger than age 7, results of 7-23 age groups fit their conclusions as well. One may argue that the disparities may be caused by the stimulus attribution or task procedures. Nevertheless, in our study, we reconciled the stimulus as the same arrows for different conflict types to avoid confounding factors.

S-S conflict processing may mature earlier than S-R conflict processing. In our study, maturity ages for S-R and S-S conflicts processing were 19.66 and 18.61 years, respectively. The current results are consistent with previous studies which jointly compared two types of conflicts processing in one study (Bryce et al., 2011; Davies et al., 2004; Jongen \& Jonkman, 2008; Liu et al., 2018; Ridderinkhof \& Van Der Molen, 1995). For example, Liu et al. (2018) found that 5- and 10-yearold children showed a smaller S-S conflict adaptation effect than S-R conflict, suggesting that the S-S conflict were relatively easier for young children to process than the S-R conflict. These results imply that for early childhood, the S-R conflict might be more difficult and involve more cognitive resources to detect or overcome. In contrast to our findings, Cragg (2016) tested a modified color Flanker task and reported that S-R conflict processing matured earlier than S-S conflict processing. However, the S-R conflict stimuli of this task were mixed with the S-S conflict. Besides, participants were asked to respond only by the middle three fingers of the right hand with limited spatial distance. The S-R conflict effect might be weakened so that no difference between children and adults was observed.

\section{Insights and limitations}


The paradigm we adopted in the current study combined S-R and S-S conflicts in a single task with a consistent arrow stimulus design. It provided us the possibility to compare different types of conflicts processing with the same cognitive representation. The Simon-spatial-Stroop task is an effective tool for conducting cognitive assessments of different ages. Further research can use our task to explore the developmental correlation between conflict processing capacity and other cognitive functions, and dynamic neurodevelopmental mechanisms underlying conflict processing. Compared with other developmental cognitive function laboratory studies, our study is large population-based, and employs consecutive age spans of children and adult participants. It provides relatively robust and reliable results for the development study and makes it possible to draw the developmental trajectories of conflict processing and explore the critical developmental period of conflict control. Furthermore, our findings contribute to the DO theory and proved the domainspecific model of conflict processing from a developmental perspective. The current findings provide normal development of conflict processing, which also serves to detect developmental deficits or disorders of executive control. However, several limits exist in the present research. Firstly, we sampled participants from 7- to 23-year-olds focusing mainly on children, adolescents, and adults. Future research is still needed to discover the development of conflict control for preschool children, middle-aged crowd, and especially the old. Secondly, we only tested SRC effects across different age span. Other individual differences like working memory capacity, intelligence, socioeconomic status may also be associated with cognitive control performance, which are not involved in the current research. Thirdly, all the participants are Chinese. Different findings from most previous research could be due to cultural differences with participants from other countries.

\section{Conclusion}


By using the Simon-spatial-Stroop task, the current study shows that the crucial developmental period for conflict processing is from childhood to early adolescent and the full maturity develops into young adulthood. Furthermore, S-R and S-S conflicts processing showed domain-specific patterns from an early age, and S-S conflict processing may mature earlier than S-R conflict processing. We suggest that these findings reveal the detached development trajectories of S-R and S-S conflict processing. Our study can serve to deepen the understanding of conflict control mechanisms and development of mental disorders interventions.

\section{Acknowledgements}

We appreciate contributions of all the participants, parents and schools to support our research.

We particularly thank Xi-Nian Zuo and Danfeng Li for helpful suggestions on the manuscript.

\section{References}

Ahmad, O. B., Boschi-Pinto, C., Lopez, A. D., Murray, C. JL., Lozano, R., Inoue, M. (2001). Age standardization of rates: A new WHO standard. Retrieved from https://www.who.int/healthinfo/paper31.pdf

Aite, A., Cassotti, M., Linzarini, A., Osmont, A., Houde, O., \& Borst, G. (2018). Adolescents' inhibitory control: Keep it cool or lose control. Developmental Science, 21, e12491. https://doi.org/10.1111/desc.12491

Akshoomoff, N., Brown, T. T., Bakeman, R., Hagler, D. J., \& Pediat Imaging Neurocognition, G. (2018). Developmental differentiation of executive functions on the NIH Toolbox Cognition Battery. Neuropsychology, 32, 777-783. https://doi.org/10.1037/neu0000476

Arias-Carrión, O., \& Salama, M. (2012). Reward-seeking behavior and addiction: Cause or cog? 
Current Drug Abuse Reviews, 5, 178-189. https://doi.org/10.2174/1874473711205030178

Barkley, R. A. (1997). Behavioral inhibition, sustained attention, and executive functions: Constructing a unifying theory of ADHD. Psychological Bulletin, 121, 65. https://doi.org/10.1037/0033-2909.121.1.65

Berenbaum, S. A., Beltz, A. M., \& Corley, R. (2015). The importance of puberty for adolescent development: Conceptualization and measurement. Advances in Child Development and Behavior, 48, 53-92. https://doi.org/10.1016/bs.acdb.2014.11.002

Best, J. R., Miller, P. H., \& Naglieri, J. A. (2011). Relations between executive function and academic achievement from ages 5 to 17 in a large, representative national sample. Learning and Individual Differences, 21, 327-336. https://doi.org/10.1016/j.lindif.2011.01.007

Bossert, M., Kaurin, A., Preckel, F., \& Frings, C. (2014). Response-compatibility effects in children. European Journal of Developmental Psychology, 11, 90-101. https://doi.org/10.1080/17405629.2013.819286

Botvinick, M. M., Braver, T. S., Barch, D. M., Carter, C. S., \& Cohen, J. D. (2001). Conflict monitoring and cognitive control. Psychological Review, 108, 624-652. http://doi.org/10.1037/0033-295X.108.3.624

Bruyer, R., \& Brysbaert, M. (2011). Combining speed and accuracy in cognitive psychology: Is the inverse efficiency score (IES) a better dependent variable than the mean reaction time (RT) and the percentage of errors (PE)? Psychologica Belgica, 51, 5-13. http://doi.org/10.5334/pb-51-1-5

Bryce, D., Szucs, D., Soltesz, F., \& Whitebread, D. (2011). The development of inhibitory control: 
An averaged and single-trial lateralized readiness potential study. NeuroImage, 57, 671685. https://doi.org/10.1016/j.neuroimage.2010.12.006

Buetti, S., \& Kerzel, D. (2009). Conflicts during response selection affect response programming: Reactions toward the source of stimulation. Journal of Experimental Psychology: Human Perception and Performance, 35, 816-834. https://doi.org/10.1037/a0011092

Bull, R., \& Lee, K. (2014). Executive functioning and mathematics achievement. Child Development Perspectives, 8, 36-41. https://doi.org/10.1111/cdep.12059

Checa, P., Castellanos, M. C., Abundis-Gutiérrez, A., \& Rosario Rueda, M. (2014). Development of neural mechanisms of conflict and error processing during childhood: Implications for self-regulation. Frontiers in Psychology, 5, 326. https://doi.org/10.3389/fpsyg.2014.00326

Clawson, A., Clayson, P. E., Keith, C. M., Catron, C., \& Larson, M. J. (2017). Conflict and performance monitoring throughout the lifespan: An event-related potential (ERP) and temporospatial component analysis. Biological Psychology, 124, 87-99. https://doi.org/10.1016/j.biopsycho.2017.01.012

Cohen, J. D., Dunbar, K., \& McClelland, J. L. (1990). On the control of automatic processes: A parallel distributed processing account of the Stroop effect. Psychological Review, 97, 332. https://doi.org/10.1037//0033-295X.97.3.332

Cragg, L. (2016). The development of stimulus and response interference control in midchildhood. Developmental Psychology, 52, 242-252. https://doi.org/10.1037/dev0000074

Cragg, L., \& Gilmore, C. (2014). Skills underlying mathematics: The role of executive function in the development of mathematics proficiency. Trends in Neuroscience and Education, 3, 6368. https://doi.org/10.1016/j.tine.2013.12.001 
Davidson, M. C., Amso, D., Anderson, L. C., \& Diamond, A. (2006). Development of cognitive control and executive functions from 4 to 13 years: Evidence from manipulations of memory, inhibition, and task switching. Neuropsychologia, 44, 2037-2078. https://doi.org/10.1016/j.neuropsychologia.2006.02.006

Davies, P. L., Segalowitz, S. J., \& Gavin, W. J. (2004). Development of response-monitoring erps in 7- to 25-year-olds. Developmental Neuropsychology, 25, 355-376. https://doi.org/10.1207/s15326942dn2503_6

Derrfuss, J., Brass, M., Neumann, J., \& von Cramon, D. Y. (2005). Involvement of the inferior frontal junction in cognitive control: Meta-analyses of switching and Stroop studies. Human Brain Mapping, 25, 22-34. https://doi.org/10.1002/hbm.20127

Egner, T. (2017). The Wiley Handbook of cognitive control. Oxford: John Wiley \& Sons.

Erb, C. D., \& Marcovitch, S. (2018a). Deconstructing the Gratton effect: Targeting dissociable trial sequence effects in children, pre-adolescents, and adults. Cognition, 179, 150-162. https://doi.org/10.1016/j.cognition.2018.06.007

Erb, C. D., \& Marcovitch, S. (2018b). Tracking the within-trial, cross-trial, and developmental dynamics of cognitive control: Evidence from the Simon task. Child Development, 90, e831-e848. https://doi.org/10.1111/cdev.13111

Eriksen, B. A., \& Eriksen, C. W. (1974). Effects of noise letters upon the identification of a target letter in a nonsearch task. Perception \& Psychophysics, 16, 143-149. https://doi.org/10.3758/BF03203267

Fan, J. (2014). An information theory account of cognitive control. Frontiers in Human Neuroscience, 8 , 680. https://doi.org/10.3389/fnhum.2014.00680 
Funes, M. J., Lupianez, J., \& Humphreys, G. (2010). Analyzing the generality of conflict adaptation effects. Journal of Experimental Psychology: Human Perception and Performance, 36, 147-161. https://doi.org/10.1037/a0017598

Gerstadt, C. L., Hong, Y. J., \& Diamond, A. (1994). The relationship between cognition and action: Performance of children 312-7 years old on a stroop-like day-night test. Cognition, 53, 129-153. https://doi.org/10.1016/0010-0277(94)90068-X

Gluckman, N. S., Hawes, D. J., \& Russell, A. M. T. (2016). Are callous-unemotional traits associated with conflict adaptation in childhood? Child Psychiatry \& Human Development, 47, 583592. https://doi.org/10.1007/s10578-015-0593-4

Hämmerer, D., Müller, V., \& Li, S. C. (2014). Performance monitoring across the lifespan: Still maturing post-conflict regulation in children and declining task-set monitoring in older adults. Neuroscience \& Biobehavioral Reviews, 46, 105-123. https://doi.org/10.1016/j.neubiorev.2014.06.008

Hazeltine, E., Lightman, E., Schwarb, H., \& Schumacher, E. H. (2011). The boundaries of sequential modulations: Evidence for set-level control. Journal of Experimental Psychology: Human Perception and Performance, 37, 1898-1914. https://doi.org/10.1037/a0024662

Hommel, B. (2011). The Simon effect as tool and heuristic. Acta Psychologica, 136, 189-202. https://doi.org/10.1016/j.actpsy.2010.04.011

Huizinga, M., Dolan, C. V., \& van der Molen, M. W. (2006). Age-related change in executive function: Developmental trends and a latent variable analysis. Neuropsychologia, 44, 20172036. https://doi.org/10.1016/j.neuropsychologia.2006.01.010

Jongen, E. M., \& Jonkman, L. M. (2008). The developmental pattern of stimulus and response 
interference in a color-object Stroop task: An ERP study. BMC Neuroscience, 9, 82. https://doi.org/10.1186/1471-2202-9-82

Kornblum, S., Hasbroucq, T., \& Osman, A. (1990). Dimensional overlap: Cognitive basis for stimulus-response compatibility--a model and taxonomy. Psychological Review, 97, 253. http://doi.org/10.1037/0033-295X.97.2.253

Larson, M. J., Clawson, A., Clayson, P. E., \& South, M. (2012). Cognitive control and conflict adaptation similarities in children and adults. Developmental Neuropsychology, 37, 343357. https://doi.org/10.1080/87565641.2011.650337

Li, S. C., Hämmerer, D., Müller, V., Hommel, B., \& Lindenberger, U. (2009). Lifespan development of stimulus-response conflict cost: Similarities and differences between maturation and senescence. Psychological Research, 73, 777-785. https://doi.org/10.1007/s00426-008$0190-2$

Liu, X., Banich, M. T., Jacobson, B. L., \& Tanabe, J. L. (2004). Common and distinct neural substrates of attentional control in an integrated simon and spatial Stroop task as assessed by event-related fmri. $\quad$ Neurolmage, $\quad 22, \quad 1097-1106$. https://doi.org/10.1016/j.neuroimage.2004.02.033

Liu, X., Liu, T., Shangguan, F., Sørensen, T. A., Liu, Q., \& Shi, J. (2018). Neurodevelopment of conflict adaptation: Evidence from event-related potentials. Developmental Psychology, 54, 1347-1362. https://doi.org/10.1037/dev0000524

Liu, X., Park, Y., Gu, X., \& Fan, J. (2010). Dimensional overlap accounts for independence and integration of stimulus-response compatibility effects. Attention, Perception, \& Psychophysics, 72, 1710-1720. https://doi.org/10.3758/app.72.6.1710 
Llewellyn, D. J., Lang, I. A., Langa, K. M., \& Huppert, F. A. (2008). Cognitive function and psychological well-being: Findings from a population-based cohort. Age and Ageing, 37, 685-689. https://doi.org/10.1093/ageing/afn194

Luna, B., Garver, K. E., Urban, T. A., Lazar, N. A., \& Sweeney, J. A. (2004). Maturation of cognitive processes from late childhood to adulthood. Child Development, 75, 1357-1372. https://doi.org/10.1111/j.1467-8624.2004.00745.x

Luna, B., Thulborn, K. R., Munoz, D. P., Merriam, E. P., Garver, K. E., Minshew, N. J., Keshavan, M. S., Genovese, C. R., Eddy, W. F., \& Sweeney, J. A. (2001). Maturation of widely distributed brain function subserves cognitive development. NeuroImage, 13, 786-793. https://doi.org/10.1006/nimg.2000.0743

MacLeod, C. M. (1991). Half a century of research on the Stroop effect: An integrative review. Psychological Bulletin, 109, 163. https://doi.org/10.1037/0033-2909.109.2.163

McNeely, H. E., West, R., Christensen, B. K., \& Alain, C. (2003). Neurophysiological evidence for disturbances of conflict processing in patients with schizophrenia. Journal of Abnormal Psychology, 112, 679-688. https://doi.org/10.1037/0021-843x.112.4.679

Posner, M. I., \& Rothbart, M. K. (1998). Attention, self-regulation and consciousness. Philosophical Transactions of the Royal Society B: Biological Sciences, 353, 1915-1927. https://doi.org/10.1098/rstb.1998.0344

Reuter, E. M., Vieluf, S., Koutsandreou, F., Hubner, L., Budde, H., Godde, B., \& Voelcker-Rehage, C. (2019). A non-linear relationship between selective attention and associated ERP markers across the lifespan. Frontiers in Psychology, 10, 30. https://doi.org/10.3389/fpsyg.2019.00030 
Richez, A., Olivier, G., \& Coello, Y. (2016). Stimulus-response compatibility effect in the near-far dimension: A developmental study. Frontiers in Psychology, 7, 1169. https://doi.org/10.3389/fpsyg.2016.01169

Ridderinkhof, K. R., \& van der Molen, M. W. (1995). A psychophysiological analysis of developmental differences in the ability to resist interference. Child Development, 66, 1040-1056. https://doi.org/10.1111/j.1467-8624.1995.tb00921.x

Rueda, M. R., Posner, M. I., Rothbart, M. K., \& Davis-Stober, C. P. (2004). Development of the time course for processing conflict: An event-related potentials study with 4 year olds and adults. BMC Neuroscience, 5, 39. https://doi.org/10.1186/1471-2202-5-39

Sanders, L. M. J., Hortobágyi, T., Balasingham, M., Van der Zee, E. A., \& van Heuvelen, M. J. G. (2018). Psychometric properties of a flanker task in a sample of patients with dementia: A pilot study. Dementia and Geriatric Cognitive Disorders Extra, 8, 382-392. https://doi.org/10.1159/000493750

Simon, J. R. (1969). Reactions toward the source of stimulation. Journal of Experimental Psychology, 81, 174. http://dx.doi.org/10.1037/h0027448

Simon, J. R., \& Rudell, A. P. (1967). Auditory S-R compatibility: The effect of an irrelevant cue on information processing. Journal of Applied Psychology, 51, 300. http://dx.doi.org/10.1037/h0020586

Smulders, S. F. A., Soetens, E. L. L., \& van der Molen, M. W. (2018). How do children deal with conflict? A developmental study of sequential conflict modulation. Frontiers in Psychology, 9, 766. https://doi.org/10.3389/fpsyg.2018.00766

Stroop, J. R. (1935). Studies of interference in serial verbal reactions. Journal of Experimental 
Psychology, 18, 643. http://dx.doi.org/10.1037/h0054651

Townsend, J. T., \& Ashby, F. G. (1978). Methods of modeling capacity in simple processing systems.

In N. J. Castellan \& F. Restle (Eds.), Cognitive theory (Vol. 3, pp. 199-239). Hillsdale, NJ: Lawrence Erlbaum.

Townsend, J. T., \& Ashby, F. G. (1983). Stochastic modeling of elementary psychological processes. Cambridge: Cambridge University Press.

Velanova, K., Wheeler, M. E., \& Luna, B. (2009). The maturation of task set-related activation supports late developmental improvements in inhibitory control. Journal of Neuroscience, 29, 12558-12567. https://doi.org/10.1523/jneurosci.1579-09.2009

Verbruggen, F., Notebaert, W., Liefooghe, B., \& Vandierendonck, A. (2006). Stimulus-and responseconflict-induced cognitive control in the flanker task. Psychonomic Bulletin \& Review, 13, 328-333. https://doi.org/10.3758/BF03193852

Vijayakumar, N., Op de Macks, Z., Shirtcliff, E. A., \& Pfeifer, J. H. (2018). Puberty and the human brain: Insights into adolescent development. Neuroscience and Biobehavioral Reviews, 92, 417-436. https://doi.org/10.1016/j.neubiorev.2018.06.004

Wang, K., Li, Q., Zheng, Y., Wang, H., \& Liu, X. (2014). Temporal and spectral profiles of stimulusstimulus and stimulus-response conflict processing. NeuroImage, 89, 280-288. https://doi.org/10.1016/j.neuroimage.2013.11.045

Waszak, F., Li, S. C., \& Hommel, B. (2010). The development of attentional networks: Crosssectional findings from a life span sample. Developmental Psychology, 46, 337. http://doi.org/10.1037/a0018541

Wright, B. C. (2017). What Stroop tasks can tell us about selective attention from childhood to 
adulthood. British Journal of Psychology, 108, 583-607. https://doi.org/10.1111/bjop.12230

Wright, I., Waterman, M., Prescott, H., \& Murdoch-Eaton, D. (2003). A new Stroop-like measure of inhibitory function development: Typical developmental trends. Journal of Child Psychology and Psychiatry and Allied Disciplines, 44, 561-575. https://doi.org/10.1111/1469-7610.00145

Yang, G., Nan, W., Zheng, Y., Wu, H., Li, Q., \& Liu, X. (2017). Distinct cognitive control mechanisms as revealed by modality-specific conflict adaptation effects. Journal of Experimental Psychology: Human Perception and Performance, 43, 807-818. https://doi.org/10.1037/xhp0000351

Zuo, X.-N., Kelly, C., Di Martino, A., Mennes, M., Margulies, D. S., Bangaru, S., Grzadzinski, R., Evans, A. C., Zang, Y.-F., Castellanos, F. X., \& Milham, M. P. (2010). Growing together and growing apart: Regional and sex differences in the lifespan developmental trajectories of functional homotopy. Journal of Neuroscience, 30, 15034-15043. https://doi.org/10.1523/jneurosci.2612-10.2010 


\section{Appendix A Stimulus-Response-Compatibility effect}

RT. The main effect of the age group was significant, $F(4,639)=642.68, p<.001, \eta_{\mathrm{p}}{ }^{2}=.80$. Post hoc tests indicated that 7-9 years $(\mathrm{M} \pm \mathrm{SE}=781.40 \pm 5.15 \mathrm{~ms})$ responded significantly slower than $10-12(\mathrm{M} \pm \mathrm{SE}=689.36 \pm 4.49 \mathrm{~ms}), 13-15(\mathrm{M} \pm \mathrm{SE}=517.17 \pm 4.27 \mathrm{~ms}), 16-18(\mathrm{M} \pm \mathrm{SE}=$ $511.91 \pm 5.06 \mathrm{~ms})$, and $19-23$ years $(\mathrm{M} \pm \mathrm{SE}=519.71 \pm 5.04 \mathrm{~ms})$, all $p s<.001 .10-12$ years responded significantly slower than $13-15,16-18$, and 19-23 years, $p s<.001$. No significant response differences were among 13-15, 16-18, and 19-23 years ( $p s=1.00)$. The main effect of the conflict type was significant, $F(1,639)=47.89, p<.001, \eta_{\mathrm{p}}^{2}=.07$. Participants responded significantly slower with $\mathrm{S}-\mathrm{S}$ conflict $(\mathrm{M} \pm \mathrm{SE}=605.79 \pm 2.17 \mathrm{~ms})$ than $\mathrm{S}-\mathrm{R}$ conflict $(\mathrm{M} \pm \mathrm{SE}=$ $602.03 \pm 2.17 \mathrm{~ms}), p<.001$. The main effect of congruency was also significant, $F(1,639)=2841.50$, $p<.001, \eta_{\mathrm{p}}{ }^{2}=.82$. Participants showed longer $\mathrm{RT}$ in incongruent conditions $(\mathrm{M} \pm \mathrm{SE}=623.70 \pm$ $2.18 \mathrm{~ms})$ than congruent conditions $(\mathrm{M} \pm \mathrm{SE}=584.12 \pm 2.19 \mathrm{~ms}), p<.001$. Besides, the interaction effect among age group, conflict type, and congruency was significant, $F(4,639)=7.24, p<.001$, $\eta_{\mathrm{p}}{ }^{2}=.04$. The simple effect analysis indicated that participants showed robust SRC effects both on S-R and S-S conflicts in all age groups, all $p s<.001$.

ER. The main effect of age group was significant, $F(4,639)=105.71, p<.001, \eta_{\mathrm{p}}{ }^{2}=.40$. Post hoc tests showed that 7-9 years $(\mathrm{M} \pm \mathrm{SE}=.21 \pm .01)$ had significantly higher error rates than $10-12$ $(\mathrm{M} \pm \mathrm{SE}=.14 \pm .01), 13-15(\mathrm{M} \pm \mathrm{SE}=.08 \pm .01), 16-18(\mathrm{M} \pm \mathrm{SE}=.07 \pm .01)$, and 19-23 years $(\mathrm{M}$ $\pm \mathrm{SE}=.06 \pm .01)$, all $p s<.001 .10-12$ years had significantly higher error rates than $13-15,16-18$, and 19-23 years, $p s<.001$. No significant differences were among 13-15, 16-18, and 19-23 years, $p s>.05$. The main effect of conflict type was significant, $F(1,639)=53.29, p<.001, \eta_{\mathrm{p}}{ }^{2}=.08$. Participants had significantly more errors with $\mathrm{S}-\mathrm{R}$ conflict $(\mathrm{M} \pm \mathrm{SE}=.12 \pm .003)$ than $\mathrm{S}-\mathrm{S}$ conflict 
$(\mathrm{M} \pm \mathrm{SE}=.11 \pm .003)$. The main effect of congruency was significant, $F(1,639)=1317.06, p<.001$ $\eta_{\mathrm{p}}{ }^{2}=.67$. Participants showed significantly higher error rates in incongruent conditions $(\mathrm{M} \pm \mathrm{SE}$ $=.15 \pm .003)$ than congruent conditions $(\mathrm{M} \pm \mathrm{SE}=.08 \pm .003)$. The interaction effect among age group, conflict type, and congruency was also significant, $F=4.68, p<.01, \eta_{\mathrm{p}}^{2}=.03$. The simple effect analysis showed that, participants showed robust SRC effects both on S-R and S-S conflicts in all age groups, $p s<.001$.

IES. The main effect of age group was significant, $F(4,639)=464.10, p<.001, \eta_{\mathrm{p}}{ }^{2}=.74$. Post hoc tests showed that 7-9 years $(\mathrm{M} \pm \mathrm{SE}=1019.86 \pm 10.14 \mathrm{~ms})$ had significantly higher IES than $10-12(\mathrm{M} \pm \mathrm{SE}=817.84 \pm 8.83 \mathrm{~ms}), 13-15(\mathrm{M} \pm \mathrm{SE}=565.46 \pm 8.41 \mathrm{~ms}), 16-18(\mathrm{M} \pm \mathrm{SE}=555.70$ $\pm 9.96 \mathrm{~ms})$, and $19-23$ years $(\mathrm{M} \pm \mathrm{SE}=553.38 \pm 9.92 \mathrm{~ms})$, all $p s<.001 .10-12$ years had significantly higher error rates (IES) than 13-15, 16-18, and 19-23 years, all $p s<.001$. No significant differences were among 13-15, 16-18, and 19-23 years, $p s=1.00$. The main effect of conflict type was significant, $F(1,639)=12.32, p<.001, \eta_{\mathrm{p}}{ }^{2}=.02$. Participants had significantly larger IES in S-R conflicts $(\mathrm{M} \pm \mathrm{SE}=705.95 \pm 4.31 \mathrm{~ms})$ than $\mathrm{S}-\mathrm{S}$ conflicts $(\mathrm{M} \pm \mathrm{SE}=698.95 \pm 4.4 \mathrm{~ms})$. The main effect of congruency was significant, $F(1,639)=1539.85, p<.001, \eta_{\mathrm{p}}^{2}=.71$. Participants showed significantly higher IES in incongruent conditions $(\mathrm{M} \pm \mathrm{SE}=757.83 \pm 4.98 \mathrm{~ms})$ than congruent conditions $(\mathrm{M} \pm \mathrm{SE}=647.07 \pm 3.89 \mathrm{~ms})$. The interaction effect among age group, conflict type, and congruency was also significant, $F(1,639)=15.88, p<.001, \eta_{\mathrm{p}}{ }^{2}=.09$. The simple effect analysis showed that, all age groups showed robust SRC effects on both S-R and S-S conflicts, $p s<.001$. 


\section{Appendix B Comparison between S-R and S-S SRC effect across the age span}

RT. The main effect of the age group was significant, $F(4,639)=8.14, p<.001, \eta_{\mathrm{p}}{ }^{2}=.05$. Post hoc tests indicated that $13-15$ years $(\mathrm{M} \pm \mathrm{SE}=.08 \pm .002 \mathrm{~ms})$ showed significantly larger SRC effects than 7-9 years $(\mathrm{M} \pm \mathrm{SE}=.06 \pm .003 \mathrm{~ms}, p<.001), 10-12$ years $(\mathrm{M} \pm \mathrm{SE}=.07 \pm .003 \mathrm{~ms}, p$ $<.001)$, and 16-18 years $(\mathrm{M} \pm \mathrm{SE}=.07 \pm .003 \mathrm{~ms})$, but not $19-23$ years $(\mathrm{M} \pm \mathrm{SE}=.70 \pm .003 \mathrm{~ms}, p$ $=.10$ ). Differences between 7-9, 10-12, 16-18 and 19-23 years were all not significant, $p s>.05$. The main effect of the conflict type was significant, $F(1,642)=23.03, p<.001, \eta_{\mathrm{p}}{ }^{2}=.04$. Post hoc tests showed that participants showed significantly larger SRC effects with $\mathrm{S}-\mathrm{R}$ conflict $(\mathrm{M} \pm \mathrm{SE}$ $=.07 \pm .002 \mathrm{~ms})$ than $\mathrm{S}-\mathrm{S}$ conflict $(\mathrm{M} \pm \mathrm{SE}=.06 \pm .002 \mathrm{~ms})$. The main effect of gender was not significant $\left(F(1,642)=.02, p=.88, \eta_{\mathrm{p}}{ }^{2}=.00\right)$, indicating no significant differences between female $(\mathrm{M} \pm \mathrm{SE}=.07 \pm .002 \mathrm{~ms})$ and male participants $(\mathrm{M} \pm \mathrm{SE}=.07 \pm .002 \mathrm{~ms})$. The interaction effect between age group and conflict type was also significant, $F(4,639)=4.05, p<.01, \eta_{\mathrm{p}}^{2}=.03$. The simple effect analysis showed that, participants showed higher S-R SRC effects than S-S SRC effects only in the group of 7-9 (S-R vs. $\mathrm{S}-\mathrm{S}: \mathrm{M} \pm \mathrm{SE}=.06 \pm .004 \mathrm{~ms}$ vs. $\mathrm{M} \pm \mathrm{SE}=.05 \pm .004 \mathrm{~ms}$, $p<.05$ ) and 10-12 years (S-R vs. $\mathrm{S}-\mathrm{S}: \mathrm{M} \pm \mathrm{SE}=.08 \pm .004 \mathrm{~ms}$ vs. $\mathrm{M} \pm \mathrm{SE}=.05 \pm .004 \mathrm{~ms}, p<.001$ ). After age 12, there was no difference between S-R and S-S conflict processing, $p s>.05$. The interaction effect between gender and age group was significant, $F(1,642)=4.87, p<.01, \eta_{\mathrm{p}}{ }^{2}=.03$. The simple effect analysis showed that, female had significantly larger effects than male in 7-9 years (female vs. male: $\mathrm{M} \pm \mathrm{SE}=.07 \pm .004 \mathrm{~ms}$ vs. $\mathrm{M} \pm \mathrm{SE}=.05 \pm .005 \mathrm{~ms}, p<.05$ ), and male had significantly larger effects than female in $16-18$ years (female vs. male: $\mathrm{M} \pm \mathrm{SE}=.06 \pm .004 \mathrm{~ms}$ vs. $\mathrm{M} \pm \mathrm{SE}=.07 \pm .004 \mathrm{~ms}, p<.01)$. No significant gender effect was observed in $10-12,13-15$, and 19-23 years, all $p s>.05$. There was no significant interaction effect between gender and conflict 
type $\left(F(1,642)=1.75, p=.19, \eta_{\mathrm{p}}^{2}=.003\right)$.

ER. The main effect of the age group was significant, $F(4,639)=10.83, p<.001, \eta_{p}^{2}=.07$. Post hoc tests indicated that $19-23$ years $(\mathrm{M} \pm \mathrm{SE}=.99 \pm .05)$ showed significantly larger SRC effects than 7-9 years $(\mathrm{M} \pm \mathrm{SE}=.52 \pm .06, p<.001), 10-12$ years $(\mathrm{M} \pm \mathrm{SE}=.73 \pm .05, p<.01)$, and 16-18 years $(\mathrm{M} \pm \mathrm{SE}=.72 \pm .05)$, but not 13-15 years $(\mathrm{M} \pm \mathrm{SE}=.84 \pm .43, p=.29)$. Besides, 7-9 years showed significant smaller SRC effects than 10-12 $(p<.05)$ and 13-15 years $(p<.001)$, but not 16-18 years $(p=.51)$. Difference between 10-12, 13-15, 16-18 were all not significant, $p s>.05$. The main effect of the conflict type was significant $\left(F(1,642)=135.22, p<.001, \eta_{\mathrm{p}}{ }^{2}=.18\right)$. Post hoc tests showed that participants showed significantly larger SRC effects with S-R conflict $(\mathrm{M} \pm$ $\mathrm{SE}=1.01 \pm .03)$ than $\mathrm{S}-\mathrm{S}$ conflict $(\mathrm{M} \pm \mathrm{SE}=.51 \pm .03)$. The main effect of gender was not significant $\left(F(1,642)=1.33, p=.25, \eta_{\mathrm{p}}{ }^{2}=.002\right)$, indicating no significant differences between female $(\mathrm{M} \pm$ $\mathrm{SE}=.73 \pm .03)$ and male participants $(\mathrm{M} \pm \mathrm{SE}=.79 \pm .03)$. The interaction between gender and age group was significant, $F(1,642)=4.26, p<.01, \eta_{\mathrm{p}}{ }^{2}=.03$. The simple effect analysis showed that, male had significantly larger effects than female in $13-15$ (female vs. male: $\mathrm{M} \pm \mathrm{SE}=.72 \pm .06$ vs. $\mathrm{M} \pm \mathrm{SE}=.97 \pm .06, p<.01$ ) and $19-23$ years (female vs. male: $\mathrm{M} \pm \mathrm{SE}=.87 \pm .07$ vs. $\mathrm{M} \pm \mathrm{SE}=$ $1.11 \pm .08, p<.05)$. No significant gender effect was observed in $7-9,10-12$, and $16-18$ years, all $p s>.05$. No significant interaction effect was found between age group and conflict type $(F(4,639)$ $\left.=1.56, p=.18, \eta_{\mathrm{p}}{ }^{2}=.01\right)$ nor between gender and conflict type $\left(F(1,642)=.98, p=.32, \eta_{\mathrm{p}}{ }^{2}=.002\right)$. 


\section{Appendix C Respective developmental changes of S-R and S-S SRC effects}

S-R conflict. For the RT, the main effect of age on mean response was significant, $F(4,639)=$ $624.12, p<.001$. Post hoc tests indicated that $7-9$ years $(\mathrm{M} \pm \mathrm{SE}=778.20 \pm 5.92 \mathrm{~ms})$ had significantly longer mean $\mathrm{RT}$ than $10-12(\mathrm{M} \pm \mathrm{SE}=687.23 \pm 6.12 \mathrm{~ms}), 13-15(\mathrm{M} \pm \mathrm{SE}=515.05 \pm$ $3.05 \mathrm{~ms}), 16-18(\mathrm{M} \pm \mathrm{SE}=511.00 \pm 4.14 \mathrm{~ms})$, and $19-23$ years $(\mathrm{M} \pm \mathrm{SE}=518.67 \pm 4.27 \mathrm{~ms}), p s$ $<.001 .10-12$ years had significantly longer mean RT than $13-15,16-18,19-23$ years, $p s<.001$. There were no significant differences between every two groups among 13-15, 16-18 and 19-23 years, $p s=1.00$. The main effect of age on SRC effects was significant, $F(4,639)=16.31, p<.001$. 7-9 years $(\mathrm{M} \pm \mathrm{SE}=52.77 \pm 2.89 \mathrm{~ms})$ had significantly larger $\mathrm{SRC}$ effects than $13-15(\mathrm{M} \pm \mathrm{SE}=$ $41.99 \pm 1.89 \mathrm{~ms}), 16-18(\mathrm{M} \pm \mathrm{SE}=33.45 \pm 2.24 \mathrm{~ms})$, and $19-23$ years $(\mathrm{M} \pm \mathrm{SE}=35.37 \pm 2.08 \mathrm{~ms})$ ( $p s<.001)$, but not $10-12$ years $(\mathrm{M} \pm \mathrm{SE}=53.31 \pm 2.27 \mathrm{~ms}, p=1.00) .10-12$ years had significantly larger SRC effects than 13-15, 16-18, and 19-23 years ( $p s<.01)$. Differences between 13-15, 1618 and 19-23 years were not significant, $p s>.05$.

For the ER, the main effect of age on mean response was significant, $(F(4,639)=91.10, p$ $<.001)$. Post hoc tests indicated that 7-9 years $(\mathrm{M} \pm \mathrm{SE}=.21 \pm .01)$ had significantly more error rates than $10-12(\mathrm{M} \pm \mathrm{SE}=.14 \pm .01), 13-15(\mathrm{M} \pm \mathrm{SE}=.08 \pm .005), 16-18(\mathrm{M} \pm \mathrm{SE}=.08 \pm .004)$ and 19-23 years $(\mathrm{M} \pm \mathrm{SE}=.06 \pm .004), p s<.001 .10-12$ years had significantly more error rates than 13-15, 16-18, 19-23 years, $p s<.001$. No significant differences were observed among 13-15, 16-18 and 19-23 years, $p s>.05$. The main effect of age on SRC effects was significant, $F(4,639)$ $=16.71, p<.001 .7-9$ years $(\mathrm{M} \pm \mathrm{SE}=.13 \pm .01)$ had significantly larger $\mathrm{SRC}$ effects than $13-15$ $(\mathrm{M} \pm \mathrm{SE}=.09 \pm .01), 16-18(\mathrm{M} \pm \mathrm{SE}=.07 \pm .01)$, and $19-23$ years $(\mathrm{M} \pm \mathrm{SE}=.07 \pm .01)(p s<.001)$ but not $10-12$ years $(\mathrm{M} \pm \mathrm{SE}=.12 \pm .01, p=1.00) .10-12$ years had significantly larger SRC effects 
than 13-15 $(p<.05), 16-18(p<.001)$, and 19-23 years $(p<.001)$. Differences among 13-15, 16-18 and 19-23 years were not significant, $p s>.05$.

S-S conflict. For the RT, the main effect of age was significant on mean response, $F(4,639)=$ $641.20, p<.001$. Post hoc tests indicated that $7-9$ years $(\mathrm{M} \pm \mathrm{SE}=784.60 \pm 6.09 \mathrm{~ms})$ had significantly longer mean $\mathrm{RT}$ than 10-12 $(\mathrm{M} \pm \mathrm{SE}=691.48 \pm 6.09 \mathrm{~ms}), 13-15(\mathrm{M} \pm \mathrm{SE}=519.28 \pm$ $3.08 \mathrm{~ms}), 16-18(\mathrm{M} \pm \mathrm{SE}=512.83 \pm 4.02 \mathrm{~ms})$, and $19-23$ years $(\mathrm{M} \pm \mathrm{SE}=520.75 \pm 4.13 \mathrm{~ms}), p s$ $<.001 .10-12$ years had significantly longer mean RT than $13-15,16-18,19-23$ years, $p s<.001$. There were no significant differences between every two groups among 13-15, 16-18 and 19-23 years, $p s=1.00$. However, the main effect of age on SRC effects was not significant $(F(4,639)=$ $1.90, p=.11)$.

For the ER, the main effect of age on mean response was significant, $F(4,639)=105.76, p$ $<.001$. Post hoc tests indicated that 7-9 years $(\mathrm{M} \pm \mathrm{SE}=.21 \pm .01)$ had significantly more error rates than $10-12(\mathrm{M} \pm \mathrm{SE}=.14 \pm .01), 13-15(\mathrm{M} \pm \mathrm{SE}=.07 \pm .004), 16-18(\mathrm{M} \pm \mathrm{SE}=.07 \pm .004)$, and 19-23 years $(\mathrm{M} \pm \mathrm{SE}=.05 \pm .004), p s<.001 .10-12$ years had significantly more error rates than $13-15,16-18,19-23$ years, $p s<.001$. No significant differences were observed among 13-15, 16-18 and 19-23 years, $p s>.05$. The main effect of age on SRC effects was significant, $F(4,639)$ $=5.04, p<.01 .10-12$ years $(\mathrm{M} \pm \mathrm{SE}=.06 \pm .01)$ had significantly larger $\mathrm{SRC}$ effects than 13-15 $(\mathrm{M} \pm \mathrm{SE}=.03 \pm .004), 16-18(\mathrm{M} \pm \mathrm{SE}=.03 \pm .004)$, and 19-23 years $(\mathrm{M} \pm \mathrm{SE}=.03 \pm .004)(p s$ $<.05)$, but not 7-9 years $(\mathrm{M} \pm \mathrm{SE}=.05 \pm .01, p=1.00)$. Differences among 7-9, 13-15, 16-18 and 19-23 years were not significant, $p s>.05$. 


\section{Appendix D Disparities of development between S-R and S-S conflict processing}

Table D1 summarizes Pearson correlation coefficients and significance between S-R and S-S mean response and SRC effects of RT and ER. For mean response, correlation coefficients were significant for each age group (all $p s<.001$ ). However, correlation coefficients of SRC effects were not significant across all age groups (all $p s>.05$ ).

Table D1 Correlation analyses between $S-R$ and $S-S$ conflicts

\begin{tabular}{ccccc}
\hline$r$-Correlation between & \multicolumn{2}{c}{ RT } & \multicolumn{2}{c}{ ER } \\
\cline { 2 - 5 } S-R \& S-S & mean & SRC & mean & SRC \\
\hline 7-9 year-old & $.95^{* * *}$ & .16 & $.92^{* * *}$ & .00 \\
10-12 year-old & $.98^{* * *}$ & .15 & $.86^{* * *}$ & .02 \\
$13-15$ year-old & $.96^{* * *}$ & .07 & $.83^{* * *}$ & -.01 \\
$16-18$ year-old & $.97^{* * *}$ & .18 & $.76^{* * *}$ & .15 \\
$19-23$ year-old & $.98^{* * *}$ & .11 & $.80^{* * *}$ & .16 \\
\hline Notes. ${ }^{*}$ denotes $.01<p<.05,{ }^{* *} .001<p<.01,{ }^{* * *} p<.001$
\end{tabular}

